\title{
NASA Low Power Stirling Convertor for Small Landers, Probes, and Rovers Operating in Darkness
}

\author{
Scott D. Wilson ${ }^{1}$, Nicholas A. Schifer ${ }^{2}$, Steven M. Geng ${ }^{3}$, Terry V. Reid ${ }^{4}$, \\ NASA Glenn Research Center, Cleveland, OH 44135 \\ Lawrence B. Penswick ${ }^{5}$, \\ Universities Space Research Association, Cleveland, OH 44135 \\ Michael R. Casciani ${ }^{6}$ \\ Vantage Partners, LLC., Brook Park, OH 44142
}

\begin{abstract}
A variety of mission concepts have been studied by NASA and the U. S. Department of Energy that would utilize low power Radioisotope Power Systems (RPS) for probes, landers rovers, and repeaters. These missions would contain science instruments distributed across planetary surfaces or near objects of interest where solar flux is insufficient for using solar cells. Landers could be used to provide data like radiation, temperature, pressure, seismic activity, and other surface measurements for planetary science and to inform future mission planners. The studies proposed using fractional versions of the General Purpose Heat Source (GPHS) or multiple Light Weight Radioisotope Heater Units (LWRHU) to heat power conversion technologies for science instruments and communication. Dynamic power systems are capable of higher conversion efficiencies, which could enable equal power using less fuel or more power using equal fuel, when compared to less efficient static power conversion technologies. Providing spacecraft with more power would decrease duty cycling of basic functions and, therefore, increase the quality and abundance of science data. Low power Stirling convertors are being developed at NASA Glenn Research Center (GRC) to provide future micro spacecraft with electrical power by converting heat from one or more LWRHUs. An initial design converts multiple watts of heat to one watt of electrical power output using a Stirling convertor. Development of the concept includes maturation of convertor and controller designs, performance evaluation of an evacuated metal foil insulation, and development of system interfaces. Demonstration of the convertor is planned and represents a new class of RPS with power levels an order of magnitude lower than previous practical designs.
\end{abstract}

\section{Nomenclature}

DOE = Department of Energy

GPHS = General Purpose Heat Source

GRC = Glenn Research Center

LWRHU = Light Weight Radioisotope Heater Units

MLMI = Multi-Layer Metal Insulation

RHU $\quad=$ Radioisotope Heater Unit

\footnotetext{
${ }^{1}$ Mechanical Engineer, Thermal Energy Conversion Branch, 21000 Brookpark Rd, AIAA Member.

${ }^{2}$ Mechanical Engineer, Thermal Energy Conversion Branch, 21000 Brookpark Rd, AIAA Member.

${ }^{3}$ Mechanical Engineer, Thermal Energy Conversion Branch, 21000 Brookpark Rd, AIAA Member.

${ }^{4}$ Mechanical Engineer, Thermal Energy Conversion Branch, 21000 Brookpark Rd, AIAA Member.

${ }^{5}$ Engineering Consultant, 21000 Brookpark Rd, AIAA Non-Member

${ }^{6}$ Electrical Engineer, Vantage Partners, LLC., 3000 Aerospace Parkway, Brook Park OH, AIAA Non-Member.
} 


\section{Need for Low Power RPS}

Low power Radioisotope Power System (RPS) conversion technologies that could convert very small amounts of heat to usable amounts of electric power include static Thermoelectric Couples (TEC) and dynamic Stirling convertors. Of the 51 missions studied by Jet Propulsion Laboratory, Goddard Space Flight Center, and Ames Research Center, 27 of the missions used low power systems that produced $5 \mathrm{~mW}$ to $9 \mathrm{~W}$ of electrical power. ${ }^{1}$ The mission studies contained science instruments distributed across planetary surfaces or near objects of interest to measure data like wind, temperature, pressure, seismic activity, and other surface measurements for planetary science and to inform future mission planners. One such concept is shown in Figure 1. These studies used fractional versions of the General Purpose Heat Source (GPHS) or one or more Light Weight Radioisotope Heater Units (LWRHU) as a heat source. Energy storage like batteries and super-capacitors were required for most designs to enable periodic energy intensive functions like data collection, communications, and roving. These studies utilized thermoelectric technologies capable of $2-5 \%$ conversion efficiency, some of which had been demonstrated in a laboratory environment at that time. The study concluded that as the capability of each mission increased, so did the power requirements. There is a need for small RPS to power science monitoring stations and communication repeaters. Depending on the power requirements, small RPS could be used to enable a Long Lived Global Monitoring Network on the Moon to study geophysics and exospheric science. ${ }^{2}$ Therefore, high efficiency dynamic RPS could be used to increase science data return on future missions or become mission enabling for low power applications.

While NASA GRC is developing 100 -watt class power convertor designs for use with GPHS through contracted efforts, an in-house team was assembled to assess the feasibility of high efficiency dynamic convertors at much lower power levels, suitable for use with LWRHUs. Initial efforts to develop subassemblies for a low power dynamic RPS have led to a design that would convert heat from multiple LWRHU to 1 watt of usable direct current electric power for spacecraft instrumentation and communication. ${ }^{3}$

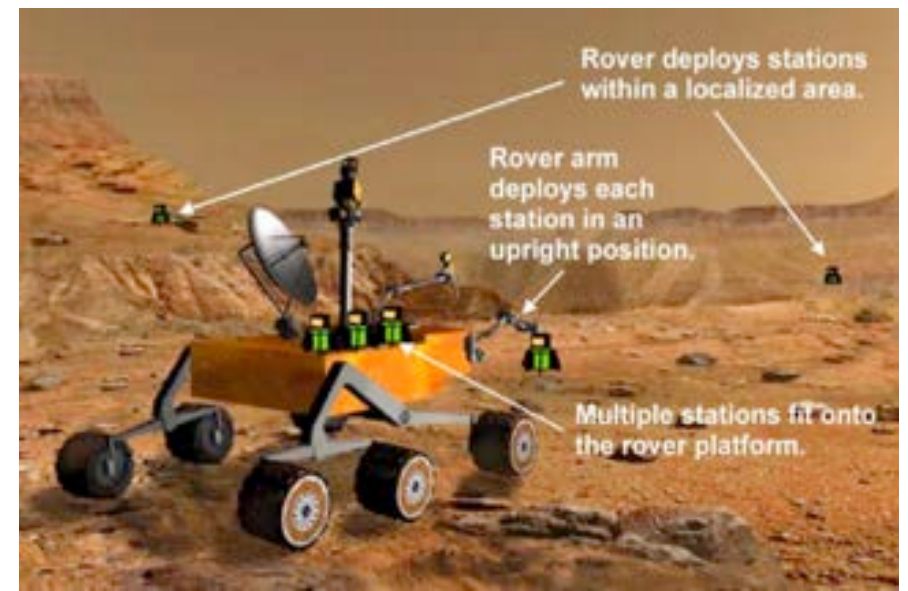

Figure 1. Conceptualization of Science Monitoring Stations Being Deployed from Rover .

\section{A. Heat Source}

Early versions of the Radioisotope Heater Unit (RHU) were developed for a lunar application and deep space exploration. ${ }^{4}$ Following their successful use on the Pioneer and Voyager missions, a higher power density RHU was developed, called the Light Weight Radioisotope Heater Unit (LWRHU). ${ }^{5}$ These smaller LWRHUs have a thermal output of 1.1 Watts at beginning of life and have a $2.6 \mathrm{~cm}$ diameter and $3.2 \mathrm{~cm}$ length. Hundreds of LWRHUs have been used to provide localized heat on numerous spacecraft over the past few decades. These small heat sources have only been proposed as heat input for power applications, but never actually used. To enable convenient packaging and a similar cylindrical footprint to the Stirling convertor, two layers of four LWRHUs were selected for the initial concept. This concept would need to prevent helium created from the decay of the Plutonium fuel from entering the evacuated insulation assembly over the life of the mission. Nuclear fuel is not available for laboratory testing so electric resistance cartridge heaters are planned to enable demonstration and performance testing. The LWRHU electric simulator utilizes four vacuum rated cartridge heaters to simulate the 8 watts thermal input anticipated from the LWRHUs. Figure 2 shows the conceptual LWRHU heat source assembly with the LWRHU volumes (orange) and the cartridge heater volumes (red). The electrical wire bus will be powered using a variable voltage power supply.
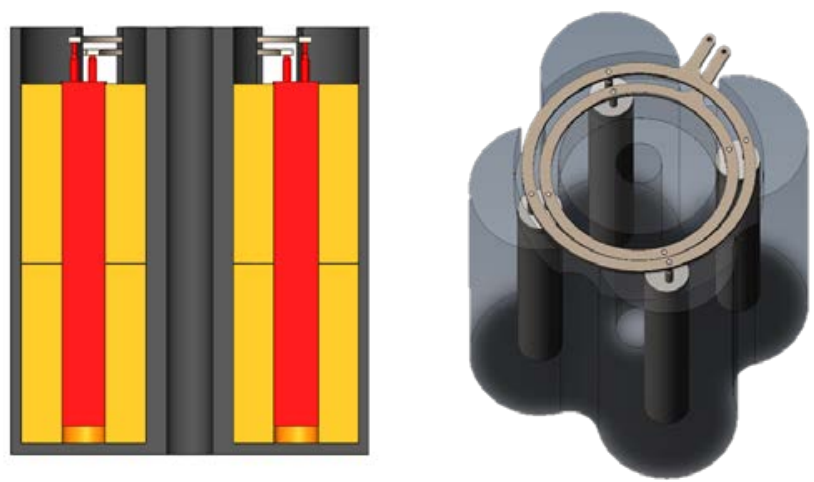

Figure 2. Conceptual LWRHU heat source assembly with LWRHU volume shown in orange and cartridge heater volume shown in red (left) and electrical wire bus (right). 


\section{B. Insulation}

The heat flux coming from the surface of a LWRHU is about $274 \mathrm{~W} / \mathrm{m}^{2}$ while the heat flux from a GPHS is about 11,000 $\mathrm{W} / \mathrm{m}^{2}$. With such little heat available from the LWRHU, a highly effective insulation package is needed in order to achieve high efficiency and the desired hot-end temperatures for the Stirling convertor. To achieve that goal, a multi-layer metal insulation (MLMI) design is being provided by Peregrine Falcon Corporation under contract with GRC. The initial design utilizes metal foils to shield the heat that would be available from eight LWRHUs. Figure 3 shows a CAD image of the MLMI with the electric heat source, Stirling thermal simulator, and fluid heat rejector. The MLMI package utilizes strategically located thin metallic shields to minimize heat loss to the environment. The design is evacuated to eliminate convection heat transfer and minimize parasitic conduction losses at internal interfaces.

The Stirling thermal simulator is shown in Figure 3. The outer surfaces of the thermal simulator create a hermetic barrier between atmosphere and the evacuated insulation package. The thermal simulator is welded to a flange (not shown) to enable removal and inspection of the Stirling thermal simulator. The insertion rod is instrumented with thermocouples to enable calculation of heat transfer through the assembly and validation of thermal models. The rod is external to the evacuated volume so it can be removed without disrupting the vacuum environment. A spring cup assembly is used to provide a light axial load to the rod, ensuring adequate contact during the test. A fluid heat exchanger is included to remove heat at the cold end of the assembly. This assembly should be adequate for testing in air or vacuum.

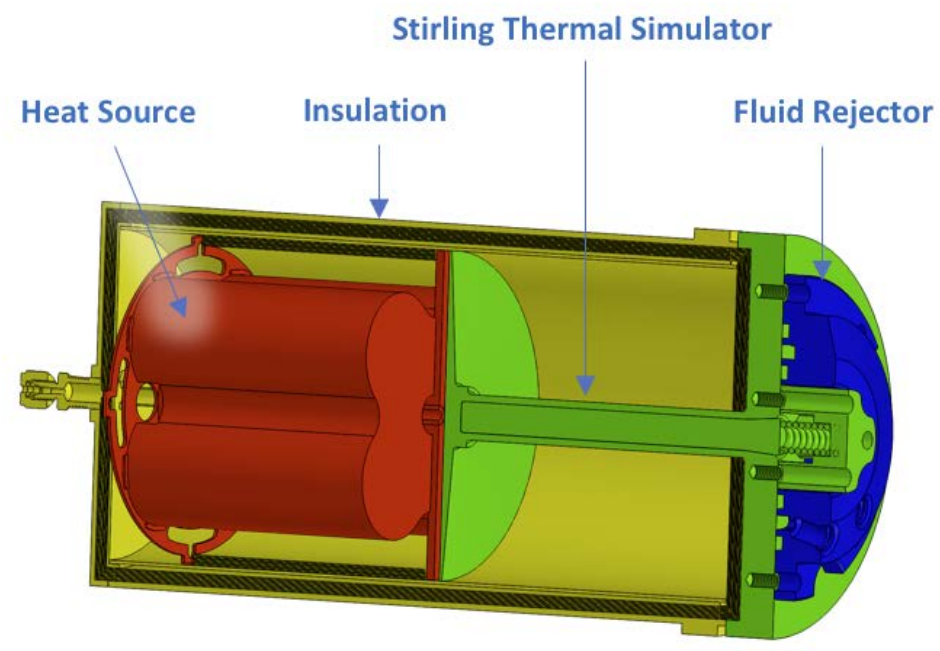

Figure 3. Multi-Layer Metal Insulation Functional Demonstration Hardware, including the electric heat source, Stirling thermal simulator, and fluid rejector.

\section{1-Watt RPS}

The 1-Watt RPS is being developed to provide power options for micro spacecraft or communication repeaters. Development efforts include maturation of the major subassemblies that make up the small RPS, including a heat source assembly, Stirling convertor, electrical controller, and the insulation package and structure. The design effort has focused on minimization of thermal and electrical losses for the insulation, convertor, and controller while providing a notional heat source assembly design. The heat source assembly would need further development to satisfy any safety requirements levied by the Department of Energy (DOE). The initial design currently contains a gas duct that connects the alternator to the engine but smaller configurations have been envisioned. Figure 4 shows an advanced concept that integrates the alternator and engine using a mounting structure and internal gas passage, reducing the overall length. This RPS concept has an overall length of roughly $32 \mathrm{~cm}$ and an $11 \mathrm{~cm}$ diameter. The heat source is mounted inside the insulation package and is radially constrained using point contacts to minimize internal thermal losses. The heat source and Stirling hot end are radiatively coupled using closely spaced plates. The Stirling convertor is constrained at the cold end and the heater head is radially constrained using point contacts, similar to the heat source. This design would avoid mechanical loading of the Stirling heater head while still enabling an adequate Stirling hot-end temperature. The controller could be encapsulated in the housing and kept warm by the 4 watts of waste heat available from the heat rejection flange located on the Stirling convertor. The current concepts have a total mass of under $3 \mathrm{~kg}$. 

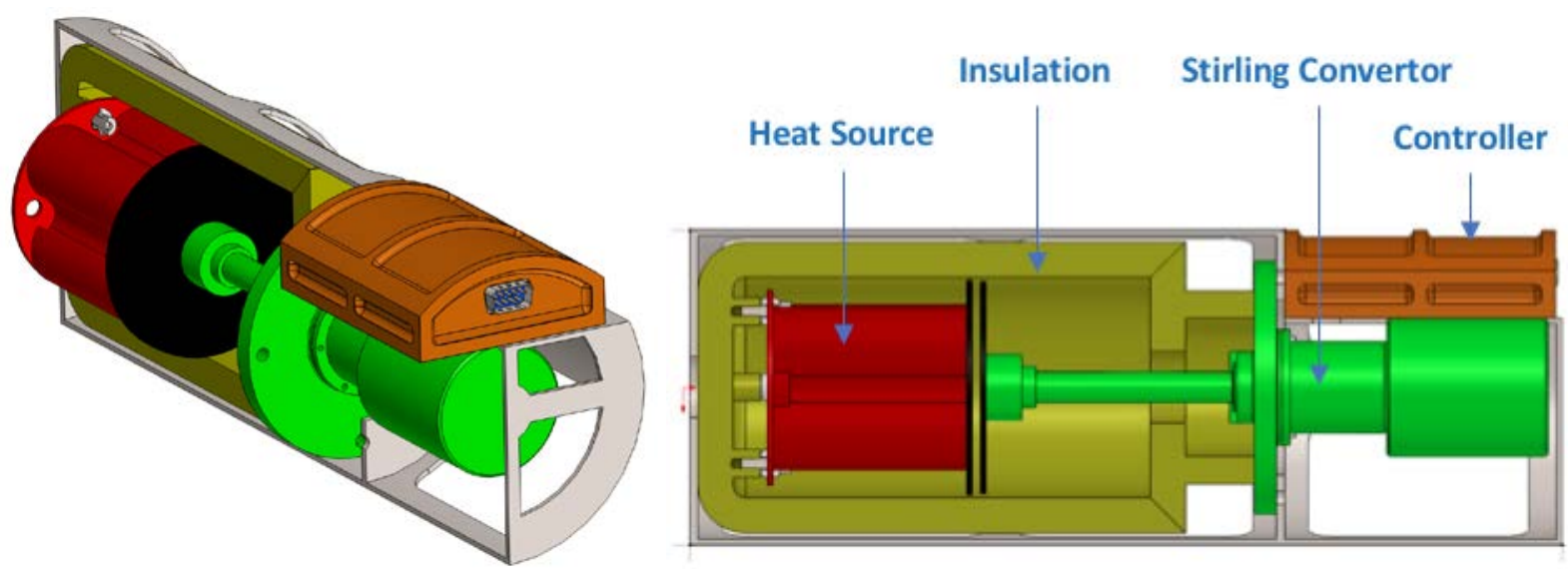

Figure 4. Conceptual Design for 1-Watt RPS, including heat source, insulation, Stirling convertor and controller.

Proof-of-concept hardware has been designed for easy assembly in a laboratory environment and is being prepared to support initial testing. A split-Stirling configuration was selected among a field of options and utilizes a gap regenerator and flexure bearings. The engine and alternator design parameters include a mean charge pressure of 7.5 bar and hot-end temperature of $350{ }^{\circ} \mathrm{C}$, both of which are considered to be relatively low compared to higher power designs for space. The hot-end temperature was selected in concert with anticipated insulation losses and an assumed value for maximum heat source surface temperature of $400{ }^{\circ} \mathrm{C}$. The Stirling cycle utilizes an operating frequency of $100 \mathrm{~Hz}$ and displacer and piston amplitudes of $2 \mathrm{~mm}$ and $4 \mathrm{~mm}$, respectively. The initial design, shown in Figure 5, does not emphasize small size or low mass. The design was optimized for ease of inspection and parameter measurement, features that would not necessarily be present in flight designs. A thick-wall gas duct was used in place of a small diameter gas line to enable testing of two different alternator designs and internal position sensors were included for displacer and piston position measurements and a transducer was included for measurement of the compression-space dynamic pressure. Future versions will be used to address minimization of sensors, interfaces, and containment vessel mass/size.

TABLE I. 1-Watt Stirling Convertor Design Parameters.

\begin{tabular}{ll}
\hline Parameter & Target \\
\hline \hline Electrical output (W) & 1.3 \\
Thermal input Qin (W) & 6.8 \\
Convertor Efficiency (\%) & 20 \\
Alternator Efficiency (\%) & 90 \\
$\operatorname{Ta}\left({ }^{\circ} \mathrm{C}\right)$ & 350 \\
$\operatorname{Tr}\left({ }^{\circ} \mathrm{C}\right)$ & 50 \\
Frequency (Hz) & 100 \\
Mean pressure (Bar) & 7.6 \\
Pressure amplitude (Bar) & 0.9 \\
Displacer amplitude (mm) & 2.0 \\
Piston amplitude (mm) & 4.5 \\
\hline
\end{tabular}

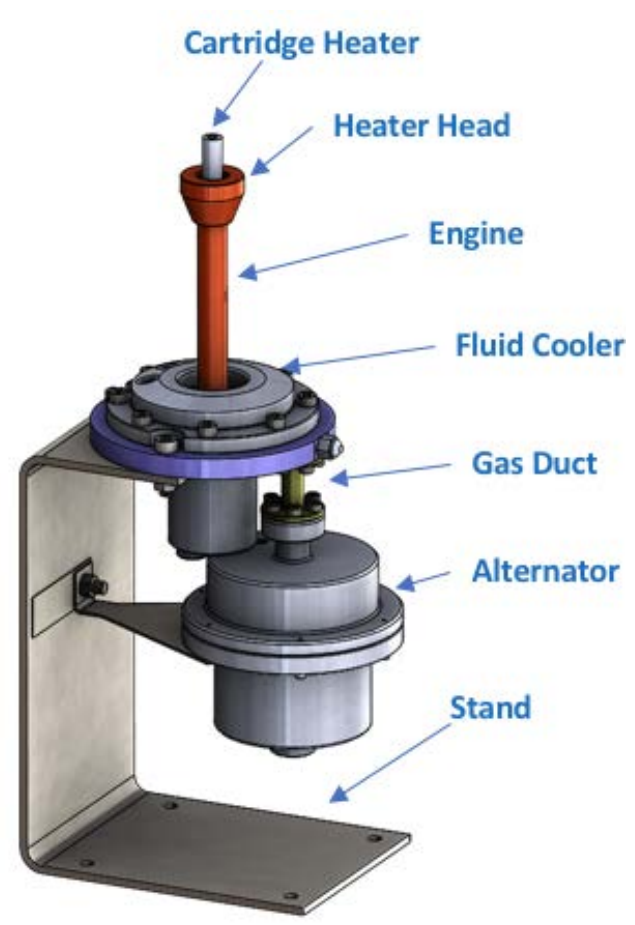

Figure 5. Proof-of-Concept Design. Insulation not shown. 


\section{A. Component Testing}

The baseline alternator design for the 1-Watt Stirling convertor employs a moving coil and stationary iron and magnet. In this moving coil design, flexure bearings are used to conduct the induced current from the coil to the terminals inside the pressure vessel. This design utilizes a simple button magnet and iron construction which has been optimized to reduce leakage of the magnetic flux fields. Figure 6 shows a cross section of the baseline alternator design.

As a potential alternative to baseline, a new type of alternator was developed at GRC using a unique magnet layout and moving coil to convert linear shaft power into electricity. ${ }^{6}$ Similar to the baseline, the moving coil is supported by flexure bearings which also conduct the induced current from the coil to the terminals. A key feature of this new concept is the ultralow inductance, which could eliminate the need for power factor correction and associated physical or digital tuning capacitors required by the controller to maximum the power factor. Initial fabrication has been completed and characterization testing of this low inductance alternator has been initiated using the test rig shown in Figure 7.

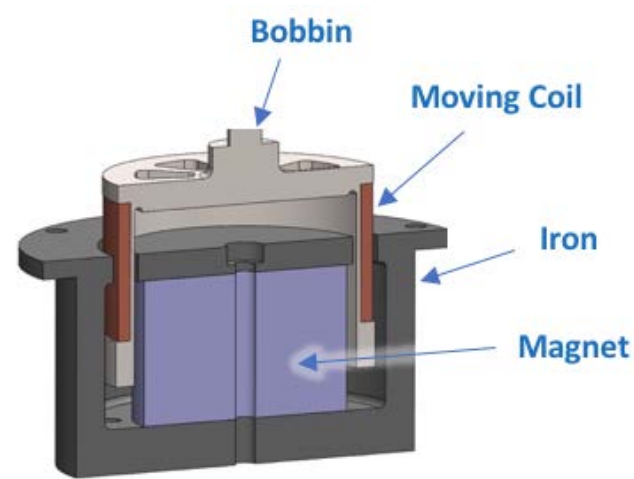

Figure 6. Baseline Moving Coil Design.

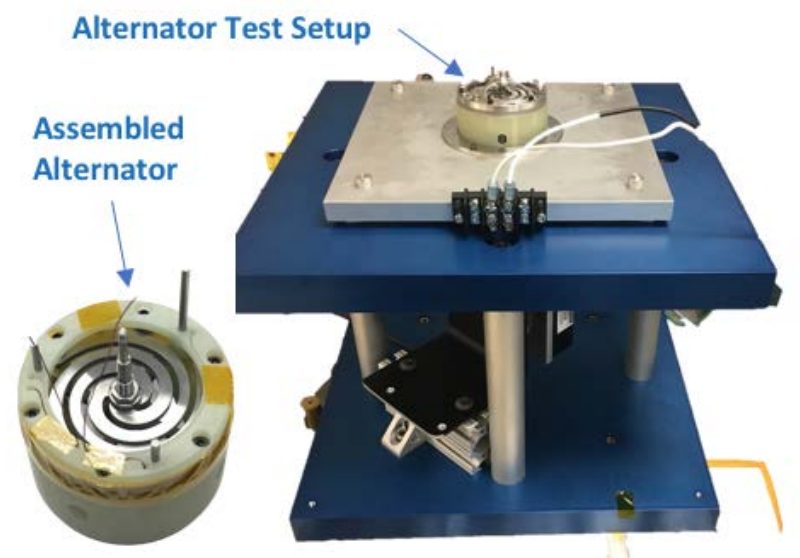

Figure 7. Alternator Characterization Test Rig.

A flexure test rig, shown in Figure 8, was also developed to enable fatigue testing of flexures at the design frequency through a range of amplitudes that exceed the design amplitude. The COMSOL Multiphysics finite element modeling software was used to model varying flexure designs and predict failure for a given deflection mode and value. Those displacer and piston flexures were then fabricated using chemical etching method. Subsequent testing of those designs was used to develop the stress versus number of cycles (S-N) curves, representing cyclic stress vs. number of cycles to failure. However, the S-N curve could only be created for the displacer flexure because the motor amplitude was insufficient to fail any of the piston flexures. The displacer flexure test amplitudes varied from $3.4 \mathrm{~mm}$ to $5 \mathrm{~mm}$, or 1.7 to 2.5 times higher than the nominal amplitude. These tests helped identify stress margins for desired design life of 20 years. Flexures have been fabricated and tested for two different materials: 1) 1095 carbon spring steel and Sandvik 7c27mo2. This first flexures were fabricated using the 1095 carbon spring steel due to long lead times to receive the Sandvik material, the need to begin screening designs, and the need to develop prediction methods for design life. Through literature search, the 1095 spring steel was found to have a better endurance fatigue limit on the order of 1,000 MPa compared to the Sandvik limit of $710 \mathrm{MPa}$; however, the Sandvik has the advantage of corrosion resistance, which is why it was selected. Both flexure designs were developed using the material properties and stress limit for Sandvik. Figure 8 also shows the S-N curve developed for 1095 spring steel displacer flexures, which shows plenty of stress margin between the maximum hard-stop amplitude of the device and the expected stress for failure based on test results. The stress was calculated for a given amplitude using COMSOL finite element analysis, and the number of cycles to failure were calculated from operating frequency and time. A sharp change in the slope of the S-N curve occurs at the empirical endurance limit, which matched well to values found in literature. Logarithmic trend lines were fit to the test data to project expected design life. A S-N curve has not yet been developed for displacer flexures of the Sandvik material; however, Sandvik flexures have been tested at 1.7 times nominal amplitude for 200 million cycles without failure. The piston flexure tests could only be performed at a maximum amplitude of $6 \mathrm{~mm}$ due to the limit of the drive motor current. That is still 1.2 times higher and the nominal amplitude and a value that exceeds the hard stop in the device. Both flexure designs were tested beyond 10 million cycles, a reasonable threshold for identifying the transition from high cycle fatigue to infinite life. The 1095 spring steel and Sandvik displacer flexures have been demonstrated up to 700 million and 200 million cycles, respectively, at 1.7 times higher 
than the nominal amplitude without fracture. Similarly, the 1095 spring steel and Sandvik piston flexures have been demonstrated up to 500 million cycles and 100 million cycles, respectively, at 1.2 times higher than the nominal amplitude without fracture.
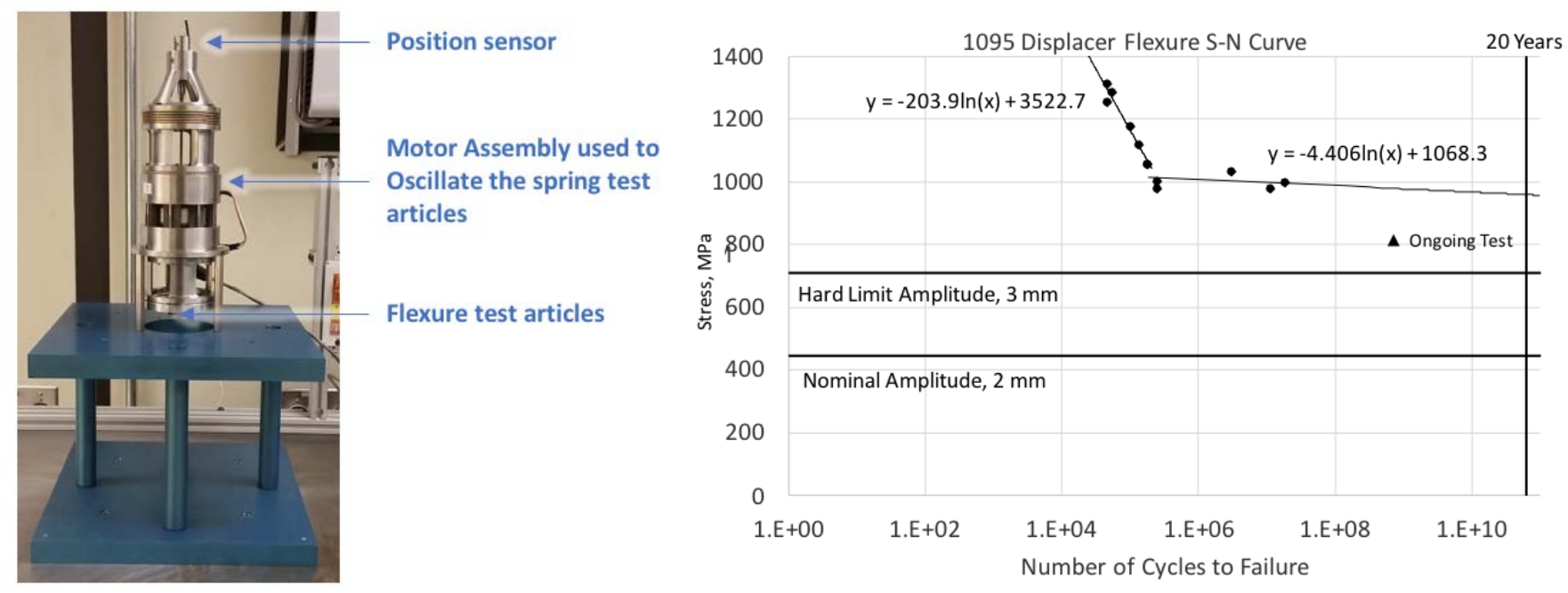

Figure 8. Flexure Test Rig and Test Data from Displacer Flexure Design (1095 spring steel).

\section{B. Controller}

The Stirling convertor needs a controller that can maintain stability and rectify the power. An analog controller design is being developed at NASA GRC to control convertor dynamics and convert alternator AC voltage to DC for a spacecraft bus or energy storage system. The basic functionality provides load control, converts the alternating current to direct current, provides wave form smoothing to improve total harmonic distortion, and shunts excess electrical power when the energy storage is full. Initial designs of the analog controller were modeled in LTspice using a linearized version of the alternator, MOSFET H-bridge to rectify AC voltage to DC, constant power circuit with a DC cap to smooth the voltage wave form and provide a DC voltage to the loads, and a synthetic capacitor to decrease Total Harmonic Distortion (THD) and improve efficiency. Active filters were modeled to successfully lower the THD to acceptable levels; THD of 4\%, 75\% controller efficiency, and over 1 We output. Breadboard testing is being performed to validate models and enable selection of an optimal design.

\section{Advanced Modeling}

The 1-Watt Stirling heat engine was modeled and optimized in Sage, a commercially available thermodynamics code used to model heat engines and cryocoolers. The Sage code often contains computational error on the order of $10-20 \%$ because it is a 1-Dimensional code and contains linearized relationships for some non-linear physical phenomena. To gain confidence in the Sage results for this very low power machine, a Computational Fluid Dynamics (CFD) model was created using the commercially available ANSYS Fluent code. There are a few key differences between the 1D Sage model and the 3D Fluent model. The Sage model connects fixed temperatures directly to the ends of the displacer cylinder, which artificially elevate the displacer temperatures and associated axial parasitic heat transfer losses. The CFD model resolves those temperatures in an evolving thermal and fluid flow field. Additionally, the Sage model assumes no motion by the displacer when resolving heat transfer in that area whereas the CFD model resolves temperature gradients and heat transfer by moving components and deforming gas volume meshes. The modeled domain was truncated at the piston face and displacer rod and, therefore, does not include seals or bounce spaces for either component. 
Figure 9 shows the 3D computational domain. The Fluent calculations use two major boundary conditions, setting the acceptor cap volume to $625 \mathrm{~K}$ (352 C) and the gas duct walls and rejector outer surface to $325 \mathrm{~K}$ (52 C). The model used the steady solver until the temperatures propagated through the entire Fluent model. Once that was complete, the transient solver was activated and motion characteristics of the displacer and piston were applied. This included mesh layering, which is applied to deforming meshes adjacent to any moving surfaces. Typically, ten cycles was enough for the various parameters to become time-periodic (where successive cycles of any parameters are identical). All output of interest is collected during the transient calculations at every time step, and are used directly or post-processed, if needed. Time histories of pressure and moving surfaces were used to build time histories of PV power for the power piston volume $\left(\mathrm{CS}_{\mathrm{P}}\right)$, compression space adjacent the displacer $\left(\mathrm{CS}_{\mathrm{D}}\right)$, and the expansion space. Once the results were

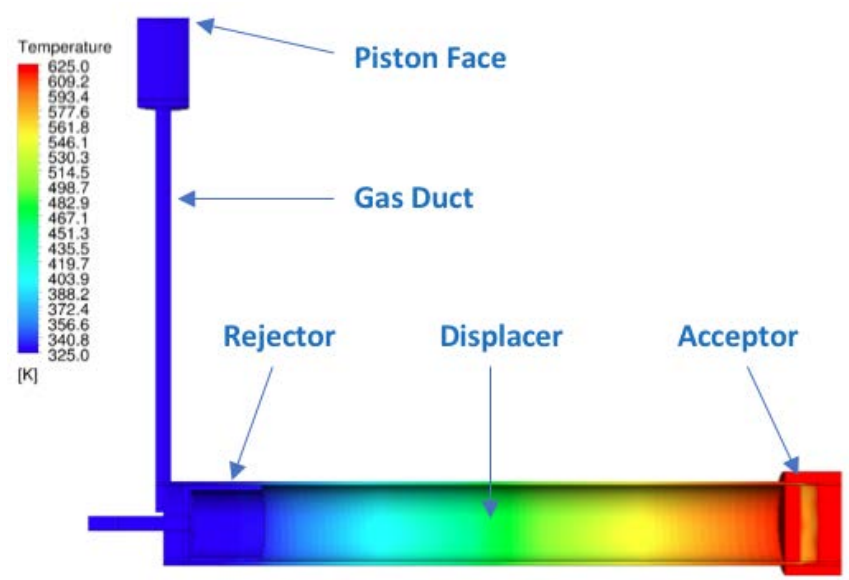

Figure 9. Temperature contours across the 3D computational domain modeled in Fluent.

confirmed to be time periodic, traces of all the relevant parameters were generated. Table II shows the pressures and heat transfer averaged over the last cycle for Fluent, as well as that predicted by Sage. Differences can be seen at the ends of the displacer cylinder, in items 4 and 5. For Sage, the ends of the displacer cylinders have fixed hot and cold end temperatures applied to it whereas Fluent resolves those temperatures. Without the extreme constant temperatures applied to the ends of the displacer cylinder in the Fluent model, the amount of heat entering the regenerator from the hot side is considerably higher when compared to the Sage model. This in turn limits the amount of heat in the Fluent model that is passed from the cylinders to the regenerator gas, which is shown as the enthalpy flux in the table.

Further, the Sage results do not directly account for shuttle heat transfer losses and show the indicated power in the compression space adjacent the displacer (CSD) and expansion space (ESD) to be equal. The Fluent model calculates these values to be slightly different, shown as Parasitic Loss in the table. Shuttle loss is not directly calculated in Sage because the displacer is not moving in for the thermal calculations. Instead, a hand calculation was used to predict shuttle losses for the Sage results. In the Fluent model, shuttle loss is calculated by monitoring the net heat transfer through the inner surfaces of the heater head and displacer cylinders adjacent the regenerator while all of the relevant volumes are in motion.

The simulation effort resulted in similar values for the various features modeled between the two codes. While there were some differences, the differences are understood and confidence that both codes are indicating this heat engine should Table II. Heat Distribution Predictions for 1D Sage and 3D Fluent models. Baseline case: Piston amplitude $=\mathbf{4} .5 \mathrm{~mm}$, displacer amplitude $=$ $2 \mathrm{~mm}$, and piston-displacer phase angle $=\mathbf{7 1 ^ { \circ }}$.

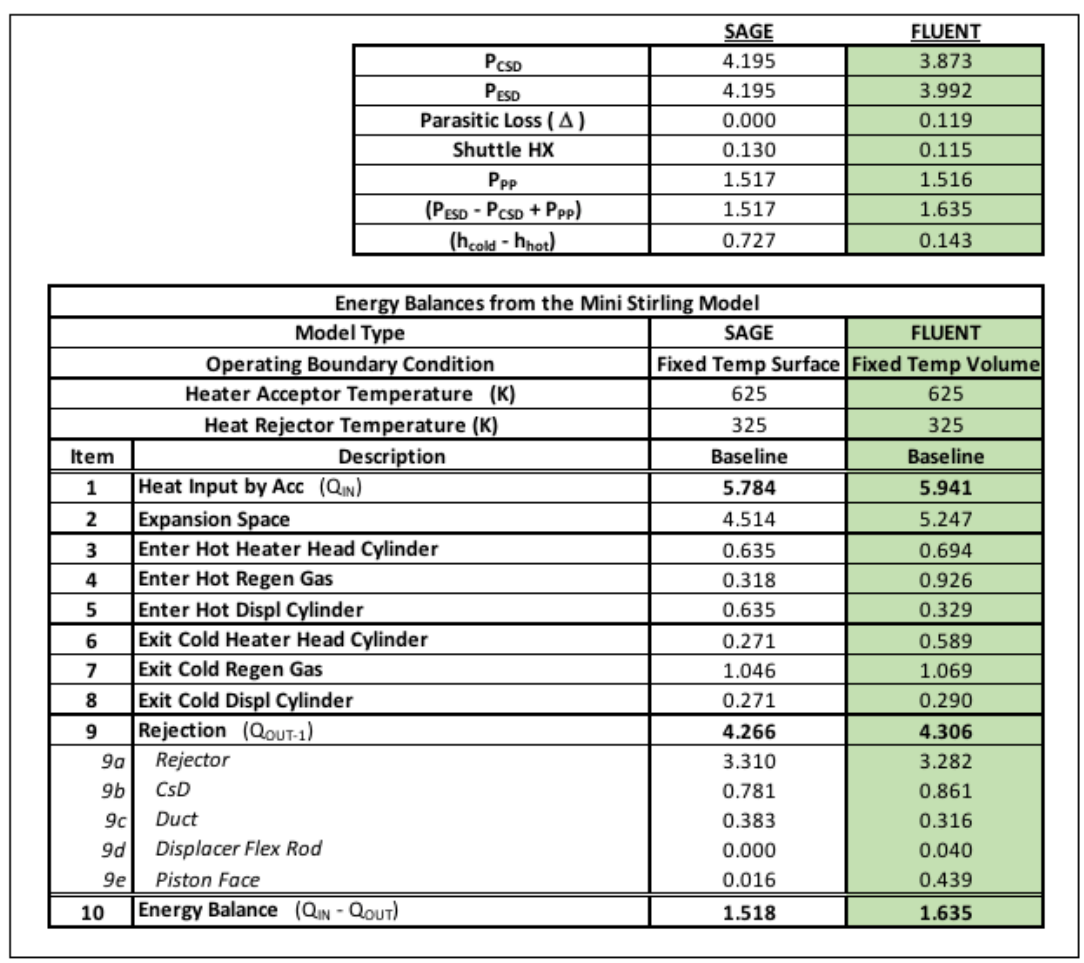
perform well. 


\section{CONCLUSIONS}

High efficiency dynamic RPS could be used to increase science data return on future missions or could be mission enabling for low power applications. NASA GRC is developing a low power dynamic RPS design that would convert heat from multiple light weight radioisotope heater units to 1 watt of usable direct current electric power for spacecraft instrumentation and communication. The power system could be used to charge batteries or capacitors for higher power burst usage. A low power free-piston Stirling convertor and controller are being fabricated by GRC for initial demonstration and a facility test station with data systems has been prepared. Development also includes maturation of a highly efficient multi-layer metal insulation package. Proof-of-concept hardware is being prepared to demonstrate this new class of power conversion device in a laboratory environment. This power system could be matured for small probes, landers, rovers and communication repeaters needed on future space exploration missions.

\section{Acknowledgments}

This work is funded through the NASA Science Mission Directorate and the Radioisotope Power Systems Program Office. The authors wish to acknowledge Daniel Goodell, Paul Schmitz, Roy Tew, and Malcolm Robbie for their contributions to the Mini Stirling development effort. Any opinions, findings, conclusions, or recommendations expressed in this article are those of the authors and do not necessarily reflect the views of NASA.

\section{References}

${ }^{1}$ NASA Office of Space Science, “Enabling Exploration with Small Radioisotope Power Systems”, JPL Pub 04-10, September 2004. 2 Jawin, E.R., Valencia, S.N., Watkins, R.N., Crowll, J.M., Neal, C.R., Schmidt, G., "Lunar Science for Landed Missions Workshop Findings Report”, Lunar Science for Landed Missions Workshop, Moffett Field. CA, January 2018.

${ }^{3}$ Wilson, S.D., Geng, S.M., Penswick, L.B., Schmitz, P.C., "Radioisotope Heater Unit-Based Stirling Power Convertor Development at NASA Glenn Research Center”, NASA/TM-2018-219704.

${ }^{4}$ National Aeronautics and Space Administration Environmental Statement for Mariner Jupiter/Saturn Project, June 1973 NASA-741756D.

${ }^{5}$ Tate, R.E., “The Light Weight Radioisotope Heater Unit (LWRHU): A Technical Description of the Reference Design”, January 1982 LA-9078-MS

${ }^{6}$ Geng, S.M., Schifer, N.A., "Development of a Low Inductance Linear Alternator for Stirling Power Convertors”, Proceedings of the Fifteenth International Energy Conversion Engineering Conference, AIAA-2707859, Atlanta, GA, 2017. 